\title{
Primary health care reform in Saudi Arabia: progress, challenges and prospects
}

Hesham Al Khashan, ${ }^{1}$ Fouad Abogazalah, ${ }^{2}$ Shaker Alomary, ${ }^{3}$ Mahmoud Nahhas, ${ }^{4}$ Ali Alwadey, ${ }^{5}$ Basema Al-Khudhair, ${ }^{6}$ Fahad Alamri, ${ }^{7}$ Nouf Aleisa, ${ }^{8}$ Nagla Mahmoud ${ }^{9}$ and Mustafa Hassanein ${ }^{9}$

${ }^{1}$ Deputy Minister's Office; ${ }^{2}$ Health Centres Affairs Directorate; ${ }^{3}$ Noncommunicable Diseases \& Health Programme Directorate; ${ }^{4}$ School Health Directorate; ${ }^{5}$ Tobacco Control Programme; ${ }^{6}$ Family Medicine Postgraduate Training Centre; ${ }^{7}$ Tele-consultation Centre; ${ }^{8}$ Health Education Directorate; ${ }^{9} \mathrm{Quality}$ and Excellence Programme, Department of Primary Health Care, Ministry of Health, Riyadh, Saudi Arabia (Correspondence to: Nagla Mahmoud: neelfadil@ moh.gov.sa).

\begin{abstract}
Background: Saudi Arabia embarked on transforming its primary health care system in 2016 to meet international standards, gain the people's trust and respond to the growing burden of noncommunicable diseases, as proposed in the Saudi Vision 2030.

Aims: This review aims to highlight the progress, identify challenges and prospects for Saudi Arabia's PHC reform process in order to make recommendations to facilitate strengthening of the PHC system.

Methods: A review of previous studies and governmental reports was undertaken to extract, analyse, synthesize and report the findings.

Results: The review has indicated that by mid-2019, the reform has contributed to an increase of $37.5 \%$ in the rate of PHC visits and $4.7 \%$ increase in patient satisfaction, enhanced coverage of rural communities (from $78 \%$ to $83 \%$ ), and contributed to increasing the screening rate for prevalent chronic diseases. However, the country still faces gaps and challenges pertaining to human resources issues, cultural and lifestyle behaviour, geography, intersectoral collaboration and PHC infrastructure.

Conclusion: PHC reform process in Saudi Arabia has demonstrated that positive change is achievable. This has been aided by building on previous accomplishments and the wealth of experience gained throughout the PHC journey in Saudi Arabia. However, despite improvement in the quality of services, continuous improvement is required to meet the rising expectations of the population.

Keywords: primary health care; reform; transformation; Saudi Arabia

Citation: Khashan H; Abogazalah F; Alomary S; Nahhas M; Alwadey A; Al-Khudhair B; et al. Primary health care reform in Saudi Arabia: progress challenges and prospects. East Mediterr Health J. 2021;27(10):1016-1026. https://doi.org/10.26719/emhj.21.042

Received: 04/11/19; accepted: 03/03/21

Copyright (C) World Health Organization (WHO) 2021. Open Access. Some rights reserved. This work is available under the CC BY-NC-SA 3.0 IGO license (https://creativecommons.org/licenses/by-nc-sa/3.0/igo).
\end{abstract}

\section{Introduction}

\section{Health care reform}

In 2016, Saudi Arabia embarked on reforming its primary health care (PHC) system as part of the wider agenda of the government. The reform was proposed in Vision 2030 (1), and was informed by an in-depth review of PHC undertaken in collaboration with the World Health Organization (WHO) (2). The aim of the reform programme is to meet international standards, gain the people's trust and respond to the growing burden of noncommunicable diseases (3).

Reform of PHC is exemplified as an integrated, family-centred approach, which has introduced new clinical pathways, screening for chronic diseases and the integration of mental health into primary care. The reform is marked by huge investments in technology and capacity-building and enhanced access to services (3).

This review highlights the progress, challenges and prospects for Saudi Arabia's PHC reform process.

\section{Background}

The original PHC concepts enshrined in the Alma Ata Declaration (1978) and accepted globally remain the same $(4,5)$ even as the world embraces a new call to action: the Sustainable Development Goals (SDGs): SDG-3 exclusively addresses health, aiming to "ensure healthy lives and promote well-being for all at all ages" $(6,7)$. Primary health care explicitly ensures a focus on equity, accessibility and quality of care (8).

While the basic concepts of PHC have remained the same, there have been changes in the context where reforms are being introduced. These reforms are aimed at solving problems and include changes in the demographic, epidemiological, educational, technical, cultural, political and economic situation (9-11).

The Saudi Arabian Ministry of Health embarked on reforming its health sector as part of a wider agenda for transforming all government sectors as envisioned in Vision 2030 (12) and the National Transformation Programme 2020 (13). 
Vision 2030 explicitly directs the reform agenda and processes towards achieving universal health coverage, ensuring healthy living and sustaining population health. It conforms with the targets of the SDGs, particularly SDG-3. Vision 2030 emphasizes the utilization of primary care as a first step through family practice and the concept of gatekeeping $(1,14)$.

In line with Vision 2030, the reform agenda proposed under the National Transformation Programme 2020 further underlines the importance of bridging the gap to accessing health services, emphasizing universal health coverage. Moreover, the National Transformation Programme 2020 aims at building primary health care as a "patient-centred model of care" and envisages the creation of "management units", thus introducing the concept of corporatization of health services (15).

The goals of the National Transformation Programme 2020 focus on improving infrastructure and safety standards and the quality of services in health care facilities; greater utilization of e-health and digital transformation; strengthening governance and accountability; and involvement of the private sector in financing and supervision (13). In view of the goals set out in Vision 2030 and the National Transformation Programme 2020, the current health sector reform is intended to separate provision, payment and regulation. A group of government-owned corporations which manage integrated networks of health care facilities will provide health care. The ministry's role will mainly focus on regulating the health sector. The system will be funded by a standalone financing entity that will focus on outcomes, enabling the system to shift towards a value-based payment model $(12,16)$.

Health care will be provided under a new model of care, a comprehensive care system for meeting health needs. This model is designed around 6 packages: keep well, planned care, maternity care, urgent care, chronic care and end of life (palliative) care (Figure 1). Five key enablers will support the implementation of the model: workforce, governance and regulations, e-health, private sector participation and appropriate payment mechanisms. The model of care design includes 42 interventions, of which 36 are directly related to PHC $(12,16)$.

Transforming the health services will require significant time to realize, hence the Ministry of Health embarked on developing a transitional plan to cover the period 2016-2020.

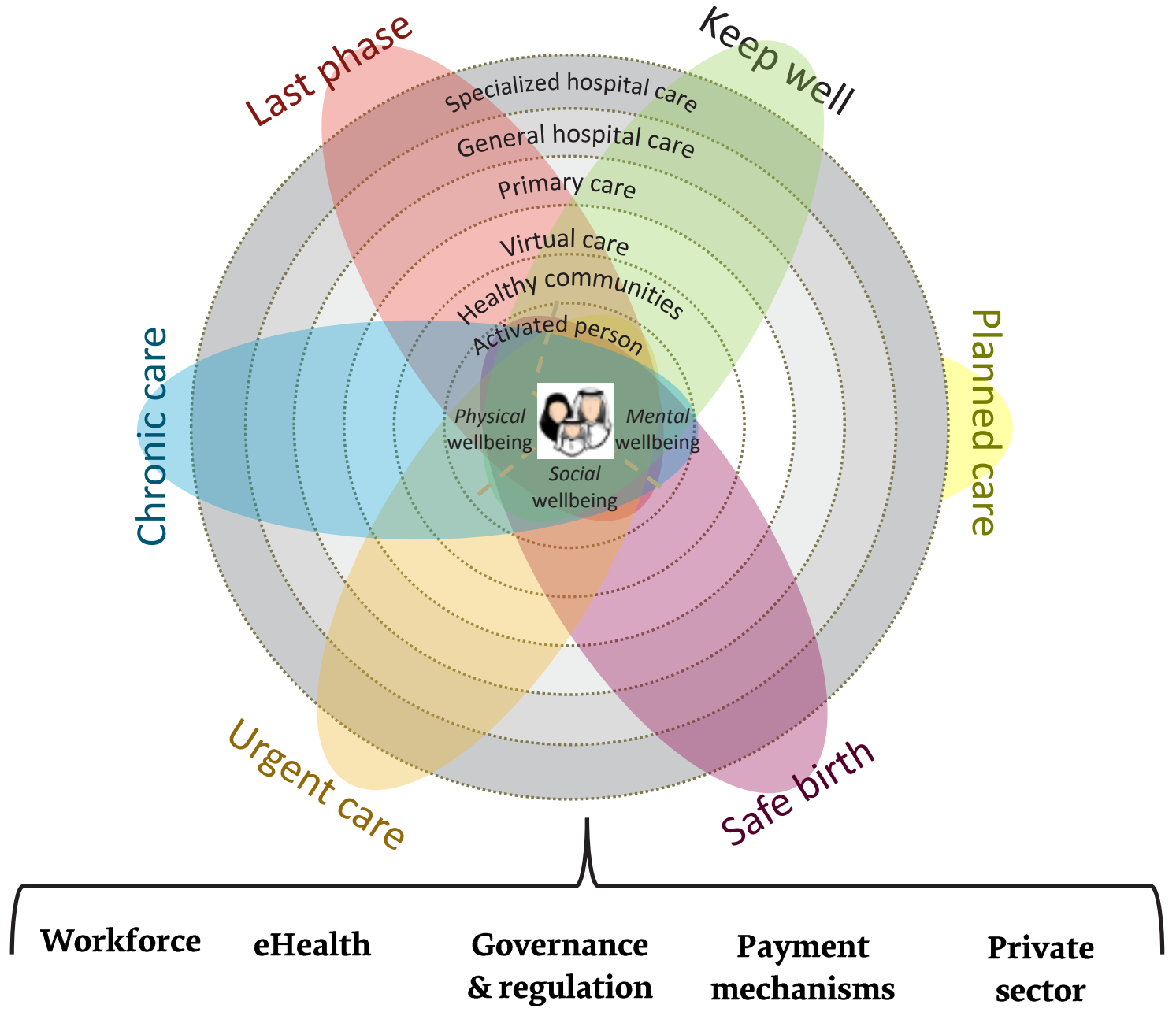




\section{Development and progress}

\section{Development of the primary health care reform transitional plan (roadmap) 2016-2020}

The primary health care reform roadmap 2016-2020 was developed as part of the government's National Transformation Programme 2020 and Vision 2030 (12). Saudi Arabia's Vision 2030 aims to bring about multisectoral reforms, including the health sector as a whole, and was formulated in response to the challenges faced by the government as a result of declining oil prices and the implications this could have on the economic and development sectors (12).

To align with Vision 2030 and the National Transformation Programme 2020, the assistant deputyship for PHC formulated a taskforce to revisit the Ministry of Health Strategic Plan (2010-2020) (17), and the PHC Strategic Plan (2010-2020) (18), both of which consider PHC as the cornerstone for the health system. An in-depth review of the PHC system guided the reform process (2). Conceptualization of the reform drew on best practices and international experience.

The PHC in-depth review, conducted in February 2016 by a team of highly experienced experts in the field of public health and PHC along with experts from the WHO, aimed at determining the challenges faced by the PHC system, providing strategic directions and proposing the best model for PHC (2). The findings of the review indicated that Saudi Arabia has achieved marked health gains during the past few decades. Primary care services are provided through an elaborate network of 2390 primary health care centres (PHCCs) that are accessible and have acceptable standards in terms of infrastructure, equipment and health workforce. The services are provided free of charge for all citizens, however the private sector provides insurance for its employees (2).

Despite the health gains, our review revealed that many challenges still remain; these are summarized below:

- an epidemiological shift from communicable to noncommunicable diseases (Table 1);

- demographic changes, with geriatric care increasingly becoming a population need;

Table 1 Prevalence and risk factors of noncommunicable diseases (NCDs) in Saudi Arabia, $2013(2,19)$

\begin{tabular}{lc} 
Key indicator & Prevalence (\%) \\
\hline Hypertension & 15.1 \\
Diabetes & 14.2 \\
Obesity/overweight & 59.4 \\
Hypercholesterolaemia & 8.5 \\
Cigarette smoking & 11.4 \\
Injuries & $9.4(2012)$ \\
NCDs Mortality & $78.0(2012)$ \\
Communicable diseases & $12.6(2012)$ \\
\hline
\end{tabular}

- enhanced stress in life and increasing prevalence of mental illness;

- $\quad$ rising cost and quality consciousness of population for $\mathrm{PHC}$;

- reduced community trust and underutilization of PHC services;

- $\quad$ PHC organization and setup is geared towards curative care;

- noncommunicable disease care and prevention programmes are not fully integrated;

- limited role of PHC facilities in ensuring essential public health functions related to health promotion and public health; PHC lacks a patient-centred approach and continuity of care.

Based on the above, a 5-year PHC reform roadmap (2016-2020) was developed. Figure 2 presents a conceptual framework of this and identifies the different tenets of the reform nested in successive layers (3).

The global burden of noncommunicable diseases has underscored the need for effective health systems based on primary care, where health promotion, disease prevention and continuity of care is provided by well-trained family physicians/general practitioners to manage and care for people with chronic diseases and their associated comorbidities (20). The findings of the PHC in-depth review indicated the need for full integration of noncommunicable diseases in $\mathrm{PHC}$ and a family medicine approach to the provision of services (2). Addressing noncommunicable diseases at the primary care level is not only essential for curbing the epidemic but also for strengthening health system equity and efficiency (21). The need to strengthen PHC had previously been highlighted in the political declaration of the United Nations High-Level Meeting for Noncommunicable Disease Prevention and Control (22). A 2019 review of the public health care system and primary care services in Saudi Arabia identified a crucial need for strengthening PHC services to address the high burden of noncommunicable diseases the country is facing (23). This view had previously been supported in a study by Almalki et al., who recommended addressing the high burden of noncommunicable diseases in future health care system reforms (24).

Family physicians and general practitioners working at PHCCs provide the foundation of health care systems and are the main figures that ensure access, connect care and endorse continuity of care for patients and their families (25). An assessment of family practice shows that family physicians constitute $10 \%$ of primary care physicians ( 636 out of 6107 ) working in $7 \%$ of PHCCs. The in-depth review revealed that PHCCs lack staff qualified in chronic disease management, and they have limited communication and interpersonal skills (17). Al-Khaldi et al, highlighted the need for improving the quality of PHC services through the development and implementation of a strategic plan for 2020 to address the shortage in 


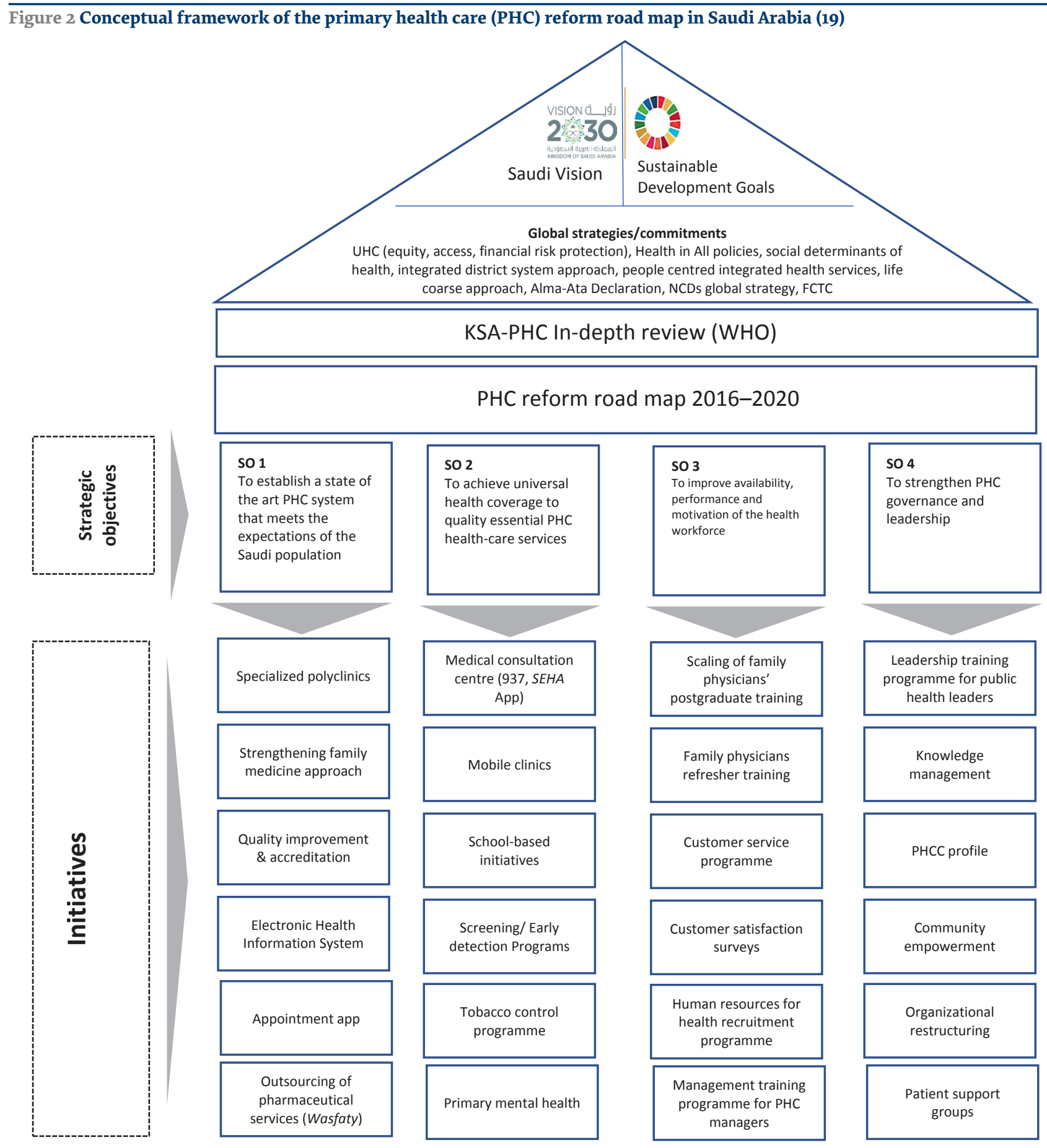

availability of qualified family physicians at PHC centres (26).

The in-depth review revealed that PHC services are not optimally utilized, only 2 visits per person per year, and do not meet the expectations of the population as the quality of care provided at the level of PHCCs is generally perceived as weak (2). To improve the quality of the services, the Ministry of Health is imposing quality standards on PHCCs set by the Saudi Central Board for Accreditation of Healthcare Institutions; this is the only national agency authorized to grant accreditation certificates to governmental and private health care facilities operating in Saudi Arabia (27). Its standards are recognized as a well-developed and highquality PHC accreditation model, on a par with Australia, Canada, Egypt, Jordan, Lebanon, New Zealand, the United Kingdom and the United States of America (28). To promote the quality of PHC services, Alghamdi et al. recommended regular assessment of patient satisfaction and patterns of utilization (29). In their evaluation of the views of $\mathrm{PHC}$ users, Alzaied et al. reported that regaining the trust can be obtained by training and continuous development to improve PHC staff performance since this affects users' decisions (30).

Developing and improving the public health services through technology is a main focus of Vision 2030 (1). 
The current health care information system is paperbased (2). The absence of an electronic system has been identified as a major contributor to the weaknesses of PHC services and infrastructure (32). Computerized services are essential to a quality health care service (33) and delivering effective patient-centred care and serving patients' needs (34). Al Asmri et al. (23) consider utilization of technology and e-health as a means of ensuring the trustworthiness of services for both the public and private sectors (31).

Saudi Arabia's Vision 2030 highlights the development of the health care sector through privatization (35). Sajjad et al. identified the need for public-private health care partnerships in order to develop a blended service delivery mechanism (36).

Bringing about change such as health systems reform is challenging due to the technical and human complexities that may exist within the system (37). Human factors in a system are more complex to modify than technical factors but are very often overlooked, leading to failures in realizing the goals and objectives of the required organizational change (38).

Leadership is one of the main factors in bringing about positive change in an organization. Effective leaders have the ability to influence or change the values, beliefs, behaviour and attitudes of employees (39), steering them towards achieving the goals of the organization (40).

Alharbi identified high organizational readiness to implement change as one of the main factors determining efficient and effective implementation of changes in the context of the National Transformation Programme and Vision 2030 (41) and recommended developing leadership talent to motivate the workforce to bring about the changes (42).

A few studies have been conducted anticipating the future $\mathrm{PHC}$ reform. A review of the public health services and the PHC services highlighted the urgent need for PHC reforms to address issues with scope, structure, infrastructure, finance, increased demand, increased costs, workforce, inequitable access to services, quality and safety of the services, the growing burden of disease, information system, management and leadership, and the referral system (23). Based on their analysis of the old, current and future health systems in Saudi Arabia, Sajjad et al. expected greater attention to be given in future reforms to the strengthening of PHCCs, automation of the system, and human resources for health training and development (36).

The current PHC reform roadmap (2016-2020) envisions that PHC facilities will be the first and optimal choice for people in Saudi Arabia through the provision of high quality, convenient services and a supporting environment that responds to public needs and expectations (3). The overall objective of the reform is to strengthen the PHC system in order to improve the trust in and utilization of the services. Four strategic objectives and a set of initiatives and interventions were proposed (Figure 2).
Primary health care reform aims at strengthening the family practice model, which is marked by provision of services by family physicians; a patient- and familycentred approach; multidisciplinary teamwork; elimination of barriers in accessing health care; automation; and a focus on quality. The model involves redefinition of the PHC services package; integration of geriatric and mental health; early detection of noncommunicable diseases; reduction of inefficiencies; redesigning of the PHC clinical pathway; and a triage system.

Reform initiatives were piloted in 5 PHCCs in each region during 2016-2017 and gradually expanded to other PHCCs. The planning process was inclusive, involving representatives of relevant $\mathrm{PHC}$ directorates and other stakeholders. This allowed for knowledge exchange, ownership and sharing of innovative ideas.

\section{Progress under primary health care reform}

To achieve Objective 1, "To establish a state of the art PHC system that meets the expectations of the Saudi Arabian population", multi-pronged interventions were carried out: implementation of the Strengthening Family Medicine Approach Initiative in 975 PHCCs out of 1000 targeted in 2019; transformation of 116 large PHCCs into polyclinics; and accreditation of 300 PHCCs by the Central Board for Accreditation of Healthcare Institutions. In addition, the health information system was automated in 675 centres; the SEHA appointment application was introduced in all PHCCs; and an electronic medical prescription system, through which dispensing of freeof-charge drugs is outsourced to private pharmacies, was piloted in 500 PHCCs (Table 2). The Strengthening Family Medicine Approach Initiative has contributed to an increase in the proportion of individuals screened for obesity, hypertension and diabetes (Figure 3).

To achieve Objective 2, "To achieve universal health coverage to quality essential PHC services", the following were implemented (Table 3): in order to improve accessibility to PHC package, 122 PHCCs were renovated, 162 substandard PHCCs replaced, 564 PHCCs supplied with equipment. Working hours were extended in 292 PHCCs.

Additionally, teleconsultation services are being offered to the whole population via a toll free number (937) as well as the SEHA appointment application, providing an average 6500 and 1500 daily teleconsultations respectively. To improve access for rural communities, 10 mobile clinics (phase I) were introduced, resulting in an increase in coverage from $78 \%$ to $83 \%$. To expand PHC at community level, 7 maternal and child health clinics were established in shopping malls. The services include vaccination, mammography and DEXA scanning, provided in collaboration with the private sector as part of their social responsibility.

Vertical expansion of the PHC package involved integration of mental health services in 852 PHCCs, expansion of comprehensive geriatric screening in all functioning PHCCs, and provision of tobacco cessation 


\begin{tabular}{|c|c|c|c|}
\hline Initiative & Indicator & $\begin{array}{c}\text { Target } \\
2017-2019\end{array}$ & $\begin{array}{l}\text { Achievements } \\
\text { mid-2019 }\end{array}$ \\
\hline Specialized polyclinics & No. operational polyclinics & 116 & $100(86 \%)$ \\
\hline PHCC quality improvement & \% PHCCs obtaining CBAHI accreditation & 400 & $300(75 \%)$ \\
\hline Electronic health information system & $\%$ PHCCs implementing e-HIS & 1000 & $675(68 \%)$ \\
\hline Strengthening family medicine approach & $\begin{array}{l}\text { No. PHCCs implementing the Strengthening } \\
\text { Family Medicine Approach Initiative }\end{array}$ & 1000 & 975 (97\%) \\
\hline SEHA appointment application & No. PHCCs & 2390 & $2390(100 \%)$ \\
\hline $\begin{array}{l}\text { Outsourcing of pharmaceutical services to private sector } \\
\text { (electronic medical prescription system) }\end{array}$ & No. PHCCs providing electronic prescriptions & 514 & $500(97 \%)$ \\
\hline
\end{tabular}

PHCC $=$ Primary health care centre.

$\mathrm{CBAHI}=$ Central Board for Accreditation of Healthcare Institutions

HIS $=$ Health information system .

services through mobile (98) and fixed (574) clinics, resulting in a smoking quittance rate of $31 \%$. Breast cancer screening was also provided through 5 mobile and 65 fixed clinics, resulting in screening of 156000 females during the past 3 years.

School-based interventions included screening for body mass index; screening for dental caries and application of local fluoride; and implementation of a periodic medical examination targeting grades $1,4,7$ and 10. All cases diagnosed were referred for further management and follow-up.

To achieve Objective 3, "To improve the availability, performance and motivation of the health workforce for better quality of PHC", the following were implemented (Table 4): the family physicians postgraduate training programme was expanded to address the shortage of family physicians. The programme commenced with the accreditation of 160 fellowship training centres by the Saudi Commission for Health Specialties and the recruitment of 600 trainers. Training is provided through 19 regional branches. These efforts have resulted in more than doubling the production of family physicians (210 in 2016 to 466 in 2019). Quality of training is ensured through undertaking an external audit, evaluation of training by trainees, supportive supervision and competition between centres.

Continuing professional development included training of 3661 PHC frontline staff on customer service and 6001 general practitioners on the latest updates in family medicine in addition to launching a training programme for nurses.

To achieve Objective 4, "To strengthen PHC governance and leadership", the following were implemented (Table 5): Training and equipping of 4 mid-level public health leaders from each of the 20 regions of the country with managerial and leadership skills, and training of 1000 PHC managers from 2390 PHCCs on leadership and management (43); additionally, the formation of community empowerment teams in 224 PHCCs and 865 patient support groups was accomplished (44).

\section{Success factors}

Early indirect results of the PHC reform roadmap (20162020) showed a national crude increase of $37.5 \%$ in the rate of PHC visits (from 2.4 visits/person/year in 2016 to 3.3 in mid-2019). In addition, patient satisfaction increased by $4.7 \%$ (71.7\% in March 2018 and 75.1\% in March 2019), according to quarterly sample surveys from 400

\section{Figure 3 Screening for diabetes (DM), hypertension (HTN) and obesity in Saudi Arabia (2017-2019)}

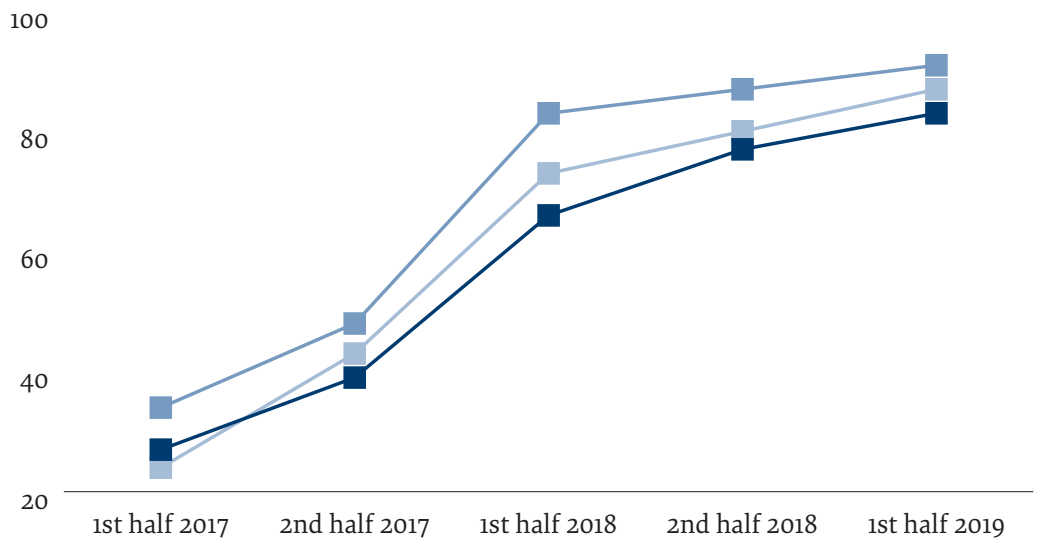




\begin{tabular}{|c|c|c|c|}
\hline Initiative & Indicator & Target, 2017-2019 & $\begin{array}{l}\text { Achievements, } \\
\text { mid-2019 }\end{array}$ \\
\hline Medical (937) & Average daily No. teleconsultations & $25 \%$ annual increase & Target achieved \\
\hline SEHA mobile application & Average daily No. teleconsultations & $25 \%$ annual increase & Target achieved \\
\hline Health coach & No. chronic disease patients coached & 1000/region & 20000 (total) \\
\hline Extended after hours services initiative & $\begin{array}{l}\text { No. PHCCs providing extended after-hours } \\
\text { services }\end{array}$ & 300 & $292(97 \%)$ \\
\hline \multirow[t]{2}{*}{ Mobile clinics initiative } & No. operational mobile clinics & 10 & $10(100 \%)$ \\
\hline & $\%$ rural communities covered (baseline $78 \%$ ) & $83 \%$ & $83 \%(100 \%)$ \\
\hline Primary mental health care initiative & No. PHCCs providing primary mental health care & 1000 & $852(85 \%)$ \\
\hline School-based obesity reduction initiative & $\begin{array}{l}\% \text { schools implementing school-based obesity } \\
\text { reduction programme }\end{array}$ & 4000 & $4015(100 \%)$ \\
\hline Periodic health examination for school students & No. students examined & $50 \%$ of grades $1,4,7,9$ & Target achieved \\
\hline $\begin{array}{l}\text { National dental health initiative for primary } \\
\text { schools }\end{array}$ & $\begin{array}{l}\% \text { schools implementing school based oral health } \\
\text { programme }\end{array}$ & 8500 & $8639(102 \%)$ \\
\hline Early detection of colorectal cancer & No. individuals aged $45-75$ years screened & 20000 & $8840(35 \%)$ \\
\hline Early detection of breast cancer & No. females aged $40-69$ years screened & 150000 & $156000(104 \%)$ \\
\hline Establishment of $\mathrm{MCH}$ clinics at shopping malls & No. MCH mall clinics established & 20 & $7(35 \%)$ \\
\hline \multirow[t]{2}{*}{ Development of PHC infrastructure } & No. PHCCs renovated & - & 122 \\
\hline & No. PHCCs replaced & - & 162 \\
\hline \multirow[t]{3}{*}{ Expansion of tobacco cessation clinics } & \multirow{2}{*}{$\begin{array}{l}\text { No. tobacco cessation clinics established (fixed \& } \\
\text { mobile) }\end{array}$} & Fixed (580) & $574(98 \%)$ \\
\hline & & Mobile (100) & $98(98 \%)$ \\
\hline & Smoking cessation rate & - & $31 \%$ \\
\hline
\end{tabular}

PHCC $=$ primary health care centre.

PHCCs conducted by Press Ganey (45). The remarkable achievements made under PHC reform could not have been achieved without the enthusiasm, dedication and collective efforts of all stakeholders. However, the following also contributed to the success of the reform:

- building on previous achievements and learning from the wealth of experience gained throughout the PHC journey in Saudi Arabia;

- political commitment for PHC reform, which is explicitly stated in Vision 2030 (12) [combating the rising burden of noncommunicable diseases is supported by the Royal Decree on Health in All Policies (2017) (46), establishment of the Saudi Center for Disease Control and Prevention (CDC) (47), and launching of the Healthy Food Regulation Strategy for banning of trans-fats (48), limitation of salt, calorie calculation (49) and adoption of plain packaging for tobacco products (50)];

- high-level commitment and strong leadership at the Ministry of Health;

- creating a swift and flexible line of recruitment for PHC;

- transfer of the National School Health Programme from the Ministry of Education to the Ministry of Health and integration of the services into PHC;

- early adoption of technology, e.g. SEHA appointment application, and enterprise resource planning;

- greater opportunities for the voices of PHC providers and consumers to be heard through technology, e.g. 937 complaints and Press Ganey surveys;

Table 4 Progress in primary health care (PHC) reform (Objective 3) in Saudi Arabia, 2019

\begin{tabular}{llcc} 
Initiative/project & Indicator & $\begin{array}{c}\text { Target } \\
\mathbf{2 0 1 7 - 2 0 1 9}\end{array}$ & $\begin{array}{c}\text { Achievement } \\
\text { mid-2019 } \\
\text { No. (\%) }\end{array}$ \\
\hline Scaling up of family physicians post-graduate training programme & No. seats offered (baseline 210) & 420 & $466(11 \%)$ \\
& No. training centres established & 20 & $19(95 \%)$ \\
Customer service training programme & \% training workshops conducted & 124 & $124(100 \%)$ \\
& & 8162 & $(3661$ trainees) \\
Refresher training for family physicians & \% general practitioners trained & $6001(67 \%)$ & $75.1 \%$ \\
Patient experience & \% patient satisfaction & 1000 & $976(98 \%)$ \\
Capacity-building of PHC managers & No. PHC managers trained & & \\
\hline
\end{tabular}

aPress Ganey survey. 


\begin{tabular}{lccc}
\hline Table 5 Progress in primary health care reform (Objective 4) in Saudi Arabia, 2019 & & \\
Initiative & Indicator & $\begin{array}{c}\text { Target } \\
\mathbf{2 0 1 7 - 2 0 1 9}\end{array}$ & $\begin{array}{c}\text { Achievement } \\
\text { mid-2019 } \\
\text { No. (\%) }\end{array}$ \\
& & 100 & $100(100 \%)$ \\
Leadership training programme for public health leaders & Public health leaders trained & 300 & $224(75 \%)$ \\
Community empowerment initiative & Community empowerment teams & 1000 & $865(86 \%)$ \\
Patient support groups & Patient support groups formed & & 100 \\
\hline
\end{tabular}

- opening the floor to innovative tools and methods (e.g. SEHA appointment application in PHC as a pilot, in addition to behavioural change approaches supported by the Central Nudge Unit at the Ministry of Health);

- formation of project management units to oversee implementation through key performance indicators; the newly introduced Ad'da health project at PHCCs offers opportunities for expert support and knowledge transfer; the project is being implemented at PHCCs following its successful implementation in hospitals; it is dedicated to improving health care delivery services across Saudi Arabia by standardizing performance measurement and reporting via an electronic dashboard (51);

- involvement and contribution of internal and external consultancy firms, and UN agencies (e.g. Saudi universities, WHO, World Bank) in the design and implementation of the reform and building the business case;

- establishment of a knowledge management unit responsible for documentation, evidence-based informed decisions, and exchange of expertise.

\section{Remaining challenges}

Despite the achievements made, several challenges remain. These are mainly due to the reform process still being in its infancy and it is estimated they will take at least 5-7 years to materialize.

Challenges include human resources issues, cultural habits and lifestyle behaviour, geography of the country, communication and collaboration between stakeholders, and PHC infrastructure.

Human resources issues include lack of incentives for the health cadre to work in remote areas, competitive salaries provided by non-Ministry of Health institutions, lack of a performance-based contracting system and filling the existing gap in human resources. Despite the expansion of family medicine training, a huge gap in number of family physicians (12000) remains at PHC level.

Challenges related to PHC infrastructure include sustainability of funding to meet the requirements for e-health, maintenance and replacement of substandard PHC facilities.

Geographical issues are a result of the vast distances between the cities, which hinders the timely supply of drugs and medicines, and impedes supervision to health centres and outreach to remote communities.

Changing behaviours towards a healthy lifestyle continues to be a major challenge.

\section{Future directions}

Despite the challenges, viable opportunities exist for strengthening the PHC system:

- aligning PHC reform with the ongoing health system transformation;

- introducing a performance-based payment model and developing an incentive scheme to attract health professionals to work in remote areas;

- strengthening multisectoral collaboration and social responsibility;

- accelerating the process of expanding the primary care IT infrastructure and use of artificial intelligence; the implementation of a health information system has laid the foundation for in-depth data analysis and measurement of clinical outcomes through the Ad'da health project:

- improving the PHC image through the establishment of 100 mega centres to function as spoke and hub;

- expansion of family medicine training programmes to fill the gap in family physicians;

- full activation of the Saudi Center for Disease Prevention and Control, with new roles and responsibilities, including Health in All policies;

- Development of short- and long-term plans for investment in leadership.

\section{Conclusion}

Primary health care reform is a long and complex process. Despite the great achievements made so far and the improvement in the quality of services provided, continuous improvement is required in order to meet the rising expectations of the population in regard to what PHC should deliver. In Saudi Arabia, PHC reform demonstrates that positive change is achievable, it requires a high level of leadership, commitment, communication and collaboration between stakeholders. It has highlighted the importance of pragmatism, paying attention to context, teamwork, national ownership, transparency, encouraging innovations, social responsibility, rewards and motivation - all key to its success. Equally 
important to the success of the reform is the existence of sustainability plans, knowledge management, leadership selection and continuing professional development. The adoption of a patient-centred approach and avenues for customers' voices to be heard has created a culture of trust between PHC providers and clients, with unlimited opportunities for reaching all aspirations of the people of Saudi Arabia.

\section{Acknowledgement}

We would like to express our deepest appreciation to all those who contributed to the different stages of the reform process. Special thanks are due to the international experts, including WHO staff, for their contribution to the PHC assessment and identifying the strategic priorities for the reform.

Funding: None.

Competing interests: None declared.

\section{Réforme des soins de santé primaires en Arabie saoudite : progrès, défis et perspectives \\ Résumé}

Contexte : En 2016, l'Arabie saoudite s'est engagée dans la transformation de son système de soins de santé primaires pour se conformer aux normes internationales, obtenir la confiance de la population et faire face à la charge de plus en plus lourde des maladies non transmissibles, conformément à la Vision saoudienne à l'horizon 2030.

Objectifs : La présente analyse vise à mettre en évidence les progrès réalisés, à identifier les défis et les perspectives du processus de réforme des soins de santé primaires (SSP) en Arabie saoudite afin de formuler des recommandations pour faciliter le renforcement du système SSP.

Méthodes: Une analyse des études et des rapports gouvernementaux précédents a été réalisée afin d'extraire, d'analyser, de synthétiser les résultats et d'en rendre compte.

Résultats : L'analyse a indiqué qu'à la mi-2019, la réforme avait contribué à une augmentation de 37,5\% du taux de consultation pour les soins de santé primaires et de $4,7 \%$ pour la satisfaction des patients, à une meilleure couverture des communautés rurales (passant de $78 \%$ à $83 \%$ ) et à l'augmentation du taux de dépistage des maladies chroniques prévalentes. Cependant, le pays est toujours confronté à des lacunes et à des défis concernant les ressources humaines, les comportements liés à la culture et au mode de vie, la géographie, la collaboration intersectorielle et les infrastructures de soins de santé primaires.

Conclusion : Le processus de réforme des soins de santé primaires en Arabie saoudite a démontré qu'un changement positif était possible. Cela a été facilité par le recours aux réalisations antérieures et à la richesse de l'expérience acquise tout au long de la mise en œuvre des soins de santé primaires en Arabie saoudite. Toutefois, malgré l'amélioration de la qualité des services, une amélioration continue est nécessaire pour répondre aux attentes grandissantes de la population.

$$
\begin{aligned}
& \text { إصلاح نظام الرعاية الصحية الأولية في المملكة العربية السعودية: التقدم المُحرَز، والتحديات الماثلة، والآفاق } \\
& \text { المستقبلية } \\
& \text { هشام الخشان، فؤاد أبو غزالة، شاكر العمري، حممود النحاس، علي الوادعي، بسمه الخضير، فهد العمري، نوف العيسى، نجلاء محمود، مصطفى } \\
& \text { حسنين } \\
& \text { الخالاصة }
\end{aligned}
$$

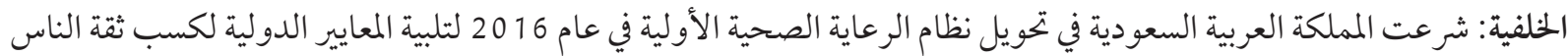

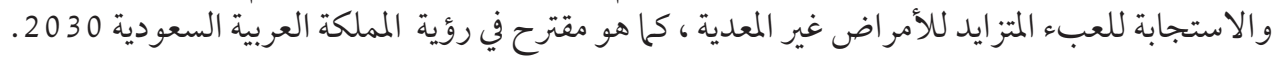

$$
\begin{aligned}
& \text { الأهداف: هدفت هذه الدراسة إلى تسليط الضوء على التقدم المحرز وتحديد التحديات والآفاق لعملية إصلاح الرعاية الصحية الأولية في المملكة }
\end{aligned}
$$

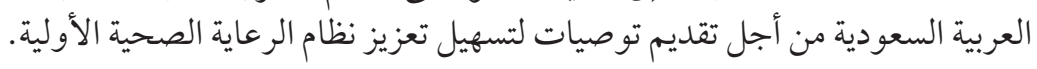

$$
\begin{aligned}
& \text { طرق البحث: تم إجراء مراجعة للدراسات السابقة والتقارير الحكومية لاستخراج وتحليل وتوليف وتقرير النتائج. }
\end{aligned}
$$

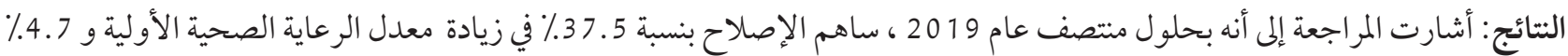

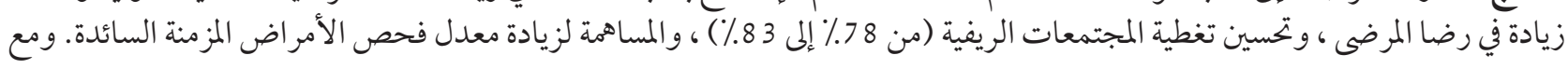




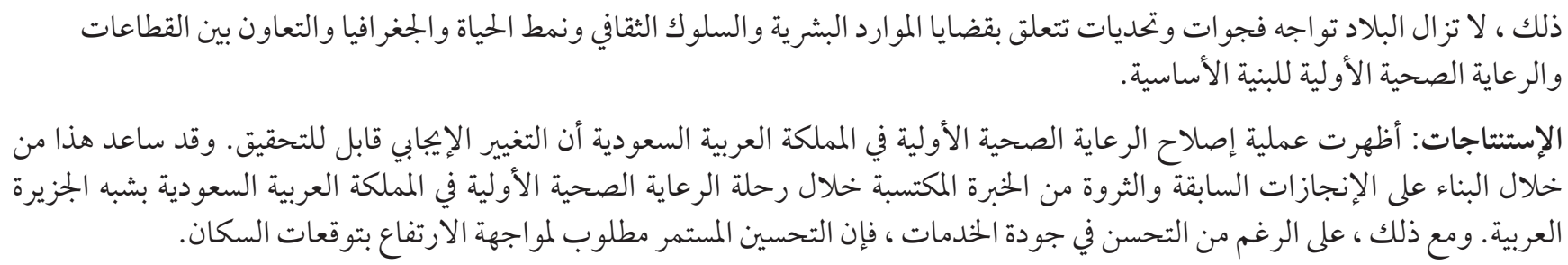

\section{References}

1. Vision 2030. Riyadh: Government of Saudi Arabia; 2016 (https://sdgs.un.org/goals, accessed 23 April 2021).

2. In-depth review of PHC: Report of WHO mission to Kingdom of Saudi Arabia, 13-18 February 2016. Cairo: World Health Organization Regional Office for the Eastern Mediterranean and Saudi Arabian Ministry of Health; 2016.

3. National PHC reform roadmap, 2016-2020. Riyadh: Ministry of Health; 2016.

4. Annual report of the director 2018, Part 2: Advancing towards universal health based on primary health care. Taking stock: 40 years of Alma-Ata. Washington DC: Pan American Health Organization; 2018 (https://www.paho.org/annual-report-of-the-director-2018/en/part-2-advancing-towards-universal-health-based-on-primary-health-care/, accessed 5 May 2019).

5. WHO. Declaration of Alma-Ata, International Conference on Primary Health Care, Alma-Ata, 6-12 September 1978. Geneva: World Health Organization; 1978 (https://www.who.int/publications/almaata_declaration_en.pdf, accessed 5 May 2019).

6. Sustainable Development Goals knowledge platform. Transforming our world: the 2030 Agenda for Sustainable Development. New York: United Nations; 2015 (https://sustainabledevelopment.un.org/post2015/transformingourworld, accessed 10 May 2019).

7. Sustainable Developments Goals in the Western Pacific, 2019. Geneva: World Health Organization; 2019 (https://www.who.int/ westernpacific/health-topics/sustainable-developmentgoals, accessed 24 August 2019).

8. Primary health care, universal health coverage and the Astana Global Conference, 2018. New York: United Nations Children's Fund: 2019 (https://www.unicef.org/health/index_primaryhealth-care.html, accessed 5 August 2019 ).

9. Global conference on primary health care: from Alma-Ata towards universal health coverage and the Sustainable Development Goals, Astana, Kazakhstan, 25 and 26 October 2018. Geneva: World Health Organization, United Nations Children's Fund. (https://www.who.int/docs/default-source/primary-health/declaration/gcphcdeclaration.pdf, accessed 27 Aug 2019).

10. Frenk J. Comparative policy analysis for health system reform. Health Policy. 1995;32:257-77.

11. Collins CD, Green AT, Hunter D. Health sector reform and the interpretation of policy context. Health Policy. 1999;47:69-83. doi:10.1016/s0168-8510(99)00003-2

12. [Health sector transformation manual.] Riyadh: Ministry of Health; (https://www.moh.gov.sa/Ministry/MediaCenter/Publications/Documents/2018-11-01010.pdf, accessed 2 May 2019) (in Arabic).

13. Vision 2030. National transformation program, 2016. Riyadh: Government of Saudi Arabia; 2016 (http://www.vision2030.gov.sa/ sites/default/files/NTP_En.pdf, accessed 2 May 2019).

14. Sustainable development: the 17 goals. New York: United Nations, Department of Economic and Social Affair; 2015 (https://sdgs. un.org/goals, accessed 5 May 2019).

15. Vision 2030. Saudi Arabia. National transformation program, delivery plan (2018-2020). Riyadh: Government of Saudi Arabia; 2016 (https://vision2030.gov.sa/sites/default/files/attachments/NTP\%20English\%20Public\%20Document_2810.pdf, accessed 23 April 2021).

16. Vision 2030. Health sector transformation strategy. Riyadh: Ministry of Health; 2017 (https://www.moh.gov.sa/en/Ministry/vro/ Documents/Healthcare-Transformation-Strategy.pdf, accessed 23 April 2021).

17. Ministry of Health Strategic Plan 2010-2020. Riyadh: Ministry of Health; 2010 (http://www.moh.gov.sa/Portal/WhatsNew/Documents/OKIstragi26op.pdf, accessed 23 April 2021).

18. [Primary health care strategic plan (2010-2020).] Riyadh: Ministry of Health; 2010 (in Arabic).

19. Noncommunicable diseases country profiles, Saudi Arabia. Geneva: World Health Organization; 2014 (https://www.who.int/ $\mathrm{nmh} /$ countries/2014/sau_en.pdf?ua=1, accessed 23 April 2021)

20. The rising importance of family medicine. Geneva: World Health Organization; 2013 (http://www.who.int/dg/speeches/2013/ family_medicine_20130626/en/, accessed 20 Dec 2020).

21. Package of essential noncommunicable (PEN) disease interventions for primary health care in low-resource settings. Geneva: World Health Organization; 2010 (https://www.who.int/nmh/publications/essential_ncd_interventions_lr_settings.pdf, accessed 23 April 2021).

22. Political declaration of the High-level Meeting of the General Assembly on the Prevention and Control of Noncommunicable Diseases, 66th Session of the General Assembly, agenda item 117. A/66/L. 1, 2011. Geneva: World Health Organization; 2011.

23. Al Asmri M, Almalki MJ, Fitzgerald G, Clark M. The public health care system and primary care services in Saudi Arabia: a system in transition. East Mediterr Health J. 2020 Apr 16;26(4):468-76. doi:10.26719/emhj.19.049 
24. Almalki M, FitzGerald G, Clark M. Health care system in Saudi Arabia: an overview. East Mediterr Health J. 2011;17(10):784-93. doi:10.26719/2011.17.10.784

25. Dimitrov BD, Fahey T. Primary health care models and suitability for provision of e-services: an overview. In: Proceedings of the transforming government workshop enabling citizen participation, social inclusion \& democracy through electronic systems \& processes. London: tGov; 2010:18-19).

26. Al-Khaldi YM, Al-Ghamdi EA, Al-Mogbil TI, Al-Khashan HI. Family medicine practice in Saudi Arabia: The current situation and proposed strategic directions plan 2020. J Family Community Med. 2017 Sep-Dec;24(3):156-63. doi: 10.4103/jfcm.JFCM_41_17

27. Alsakkak MA, Alwahabi SA, Alsalhi HM, Shugdar MA. Outcome of the first Saudi Central Board for Accreditation of Healthcare Institutions (CBAHI) primary health care accreditation cycle in Saudi Arabia. Saudi Med J. 2017 Nov;38(11):1132-6. doi:10.15537/ smj.2017.11.20760

28. Tabrizi JS, Gharibi F. Primary healthcare accreditation standards: a systematic review. Int J Health Care Qual Assur. 2019 Mar 11;32(2):310-20. doi:10.1108/IJHCQA-02-2018-0052

29. Alghamdi K, Aljohani A, Taha J, Qari L, Demyati M, Alzahrani S. Public awareness and utilization of the primary health care services in Al-Madinah, Saudi Arabia. Middle East J Family Med. 2020;18(2):33-41. doi:10.5742MEWFM.2020.93757

30. Alzaied TA, Alshammari A. An evaluation of primary healthcare centers (PHC) services: the views of users. Health Sci. J. 2016;10(2):15.

31. Noor A. The utilization of e-health in the Kingdom of Saudi Arabia. Int Res J Eng Technol. 2019;6:1229-39.

32. Hasanain R, Vallmuur K, Clark M. Progress and challenges in the implementation of electronic medical records in Saudi Arabia: a systematic review. Health Informatics. 2014;3(2). doi:10.5121/hiij.2014.3201

33. Liyanage H, Correa A, Liaw ST, Kuziemsky C, Terry AL, de Lusignan S. Does informatics enable or inhibit the delivery of patient-centred, coordinated, and quality-assured care: a delphi study: a contribution of the IMIA Primary Health Care Informatics Working Group. Yearb Med Inform. 2015 Aug 13;10(1):22-9. doi:10.15265/IY-2015-017

34. Organizational guide for the paid health services program. Riyadh: Ministry of Health; 2018 (in Arabic).

35. Rahman R. The Privatization of Health Care System in Saudi Arabia. Health Serv. Insights. 2020;13:1178632920934497. doi:10.1177/1178632920934497

36. Sajjad R, Qureshi MO. An assessment of the healthcare services in the Kingdom of Saudi Arabia: an analysis of the old, current, and future systems. Int J Healthc Manag. 2018;6:1-9. doi:10.1080/20479700.2018.1433459

37. Spinelli RJ. The applicability of Bass's model of transformational, transactional, and laissez-faire leadership in the hospital administrative environment. Hosp Top. 2006;84(2):11-8. doi:10.3200/HTPS.84.2.11-19

38. Bennett JB. Competing on healthcare analytics: The foundational approach to population health analytics. Buffalo Grove, IL: Create Space Independent Publishing Platform; 2016.

39. Ganta VC, Manukonda JK. Leadership during change and uncertainty in organizations. International J Organizational Behav Management Persp. 2014;3(3):1183.

40. Hao MJ, Yazdanifard R. How effective leadership can facilitate change in organizations through improvement and innovation. Global J Management Bus Res (A). 2015;9(1)15-6.

41. Alharbi MF. An analysis of the Saudi health-care system's readiness to change in the context of the Saudi National Health-care Plan in Vision 2030. Int J Health Sci (Qassim). 2018 May-Jun;12(3):83-7. PMID: 29896076

42. Alharbi MF. An investigation of the saudi healthcare system's readiness for change in the light of Vision 2030: the role of transformational leadership style. J Health Spec. 2018;6(2):45. doi:10.4103/jhs.JHS_142_17

43. GE Healthcare Partners: Primary health care leadership development program. Training manual. Riyadh: Ministry of Health; 2017.

44. Public health deputyship enterprise project management office weekly reports. Riyadh: Ministry of Health; 2019.

45. Patients' experience 2019 mid-year report. Riyadh: Ministry of Health; 2019.

46. Combating the rising burden of NCDs is supported by the Royal Decree on Health in All Policies. Riyadh: Ministry of Health; 2017 (www.moh.gov.sa/Ministry/MediaCenter/News/Pages/News-2017-07-09-002.aspx, accessed 27 June 2019).

47. Council of Ministers. Resolution number 200 (19/06/1434) on establishment of Saudi Center for Disease Prevention and Control (CDC). Riyadh: Public Health Authority;2013 (https://covid19.cdc.gov.sa/about-us/, accessed 23 April 2021)

48. Trans fatty acids decree (SFDA.FD 2483 /2018). Riyadh: Saudi Food and Drug Authority; 2018 (https://extranet.who.int/nutrition/ gina/sites/default/files/SAU\%202018\%20SFDA-FD-2483\%200n\%20PHO\%20ban.pdf, accessed 12 September 2019).

49. Healthy food regulation strategy. Riyadh: Saudi Food and Drug Authority; 2018. (https://www.sfda.gov.sa/ar/awareness/Documents/SFDA-HealthyFoodStrategy.pdf, accessed 23 April 2021).

50. Plain packaging of tobacco products. Riyadh: Saudi Food and Drug Authority; 2018. (https://www.tobaccocontrollaws.org/files/ live/Saudi\%20Arabia/Saudi\%20Arabia\%20-\%20Plain\%20Pkg.\%20Standard.pdf, accessed 23 April 2021).

51. Ada'a PHC project charter. Riyadh: Ministry of Health; 2019. 